\title{
Uma Educação Física Histórico-Cultural (?) Os significados das atividades da cultura corporal como uma problemática geral de pesquisa para a área.
}

\author{
A Cultural-Historical Physical Education (?) The meanings of bodily \\ culture activities as a general problematic of research for the area.
}

\section{Carolina Picchetti Nascimento ${ }^{1}$}

\begin{abstract}
RESUMO
Discuto neste ensaio alguns sentidos pedagógicos em propormos uma perspectiva Histórico-Cultural para o ensino da Educação Física. Defendo que o processo de identificação e proposição dos significados das atividades da cultura corporal constituise em uma problemática central para as pesquisas em Educação Física direcionadas a efetivar um ensino desenvolvimental na escola. Metodologicamente, analiso uma situação concreta de ensino e de aprendizagem a fim de desencadear uma discussão sobre a relação entre os conhecimentos de ensino em Educação Física e os processos de desenvolvimento dos sujeitos, professores e estudantes. A análise dessa situação procura evidenciar como o sistema de conhecimentos a serem trabalhados na dinâmica da atividade pedagógica da Educação Física direciona de forma decisiva as ações com as quais

ABSTRACT

I discuss in this essay some pedagogical senses when one proposes a "Cultural-Historical perspective" for Physical Education teaching. I argue that the process of identifying and proposing the meanings of bodily culture activities is a central problem in Physical Education research aimed at achieving a developmental teaching at school. Methodologically, I analyse a concrete situation of teaching and learning in order to trigger a discussion about the relationship between the knowledge of teaching in Physical Education and the process of development of subjects, teachers and students. The analysis of this situation seeks to show how the system of knowledge to be worked in the dynamics of the pedagogical activity of Physical Education directs in a decisive way the actions with which teachers and students may engage in their teaching and study activities with a certain content of body culture.
\end{abstract} professores e estudantes podem se engajar em suas atividades de ensino e de estudo com um determinado conteúdo da cultura corporal.

Palavras-chave: Atividade Pedagógica. Cultura Corporal. Teoria Histórico-Cultural

Keywords: Pedagogical Activity. Bodily Culture. Cultural Historical Theory.

\footnotetext{
${ }^{1}$ Integrante do Grupo de Estudo e Pesquisa sobre Atividade Pedagógica (GEPAPe) e, atualmente, é professora do Departamento de Metodologia de Ensino da Universidade Federal de Santa Catarina. E-mail: carolina_picchetti@hotmail.com
} 
1 Introdução: um ensino Histórico-Cultural para a Educação Física?

Discuto neste ensaio quais os sentidos pedagógicos existentes na proposição de uma "perspectiva Histórico-Cultural para o ensino da Educação Física". Parto da compreensão que as ideias, conceitos e teses desenvolvidos pelos autores da Teoria Histórico-Cultural constituem-se em instrumentos para reconhecermos e/ou elaborarmos os problemas de pesquisa relacionados com os processos de organização de um ensino "desenvolvimental" (DAVIDOV, 1988; DAVYDOV, 1982) no campo da Educação Física.

$\mathrm{Na}$ tradição Histórico-Cultural, o processo de desenvolvimento que se almeja promover nos sujeitos pela mediação da prática educativa escolar corresponde à formação do pensamento teórico (DAVIDOV, 1988; DAVYDOV, 1982), como uma das expressões das funções psicológicas superiores do sujeito (VYGOTSKI, 1995). Vigotski, a partir de seus estudos da década de 1930, apresentou a tese de que a aprendizagem deve promover e conduzir o desenvolvimento dos sujeitos, tendo como premissa a possibilidade e a necessidade histórica de que cada indivíduo reconstitua para si as máximas possibilidades de desenvolvimento alcançadas pela humanidade (VYGOTSKI, 1995; 1997; VYGOTSKY, 2004; LEONTIEV, 1983). É neste contexto que podemos compreender a sua tese de que "o único bom ensino é o que se adianta ao desenvolvimento" (VIGOTSKII, 1988, p.114). Na década de 1950, D. B. Elkonin e V. Davidov começam a trabalhar com as consequências práticas deste princípio em situações educacionais concretas, defendendo a tese de que o ensino escolar "deve estruturar-se de maneira que, de forma concisa, abreviada, reproduza o processo histórico real de gênese e desenvolvimento dos conhecimentos" (DAVIDOV, 1988, p.174). No Brasil, Moura (2000) e Moura et al (2016), utilizando-se do conceito de "Atividade Orientadora de Ensino", contribuem para o entendimento da atividade pedagógica como unidade entre a atividade de ensino do professor e a atividade de estudo do estudante.

A produção teórica destes autores oferece-nos princípios gerais para a proposição de uma Educação Física fundamentada na perspectiva da Teoria 
Histórico-Cultural, colocando-nos, entretanto, o desafio de propormos meios concretos para a efetivação desta tarefa.

Um caminho possível para realizarmos essa tarefa seria elegermos conceitos, teses e princípios centrais da Teoria Histórico-Cultural, sistematizando a potencialidade pedagógica e didática de cada um deles. Nesta direção, discutiríamos conceitos tais como "zona de desenvolvimento próximo" (VYGOTSKI, 1996), "funções psíquicas superiores" (VYGOTSKI, 1995), "pensamento teórico" (DAVIDOV, 1988; DAVYDOV, 1982) e "atividade" (LEONTIEV, 1978; 1983) buscando suas vinculações para a organização didáticopedagógica da Educação Física. Em que pese a relevância de apresentarmos essas sínteses conceituais em um artigo e o esforço exigido para fazê-las, parece pertinente, também, reconhecermos que semelhante procedimento de exposição costuma deixar apenas para as "considerações finais" (quando não diretamente para o leitor) a tarefa de relacionar aqueles conceitos, princípios e teses com as problemáticas específicas enfrentadas pela atividade pedagógica da Educação Física. Acabamos falando mais sobre a teoria do que com a teoria, o que resulta em deixar o nosso objeto de investigação, a atividade pedagógica (da Educação Física), à margem das discussões pretendidas.

Um segundo caminho para realizarmos a tarefa de proposição de uma Educação Física a partir da perspectiva Histórico-Cultural seria através da análise de problemas gerais e estruturais existentes na prática pedagógica da Educação Física escolar, destacando-se, ao mesmo tempo, em que medida o problema pedagógico analisado é desvelado e explicado pelos conceitos, princípios e teses da Teoria Histórico-Cultural. Embora este segundo caminho pareça nos afastar das discussões sobre a Teoria Histórico-Cultural e o ensino da Educação Física (já que não abordamos diretamente os seus conceitos) ele pode, contraditoriamente, contribuir para que nos insiramos de modo propositivo neste debate ao evidenciar, de partida, o modo como os fundamentos da teoria podem ser elaborados em problemáticas concretas de pesquisa.

Este segundo caminho de exposição exige do leitor alguma familiaridade com os conceitos da teoria aqui abordada, a fim de que acompanhe o sentido de 
levantarmos questões tais como: "quais são os conhecimentos substanciais no campo da Educação Física que contribuem para o desenvolvimento do pensamento teórico dos sujeitos?" ou "o que significa falarmos em "conhecimento teórico’ no ensino da Educação Física?”

Considerando a proposta do presente dossiê (“didáticas específicas” fundamentadas na Didática Desenvolvimental e/ou na Psicologia HistóricoCultural), e pressupondo que os leitores deste material já estejam familiarizados com algumas das ideias e conceitos centrais desta teoria, considerei pertinente, neste artigo, abordar as intervinculações entre Teoria Histórico-Cultural e Educação Física através da análise de um problema pedagógico concreto enfrentado na atividade de ensino do professor de Educação Física.

Inicio o texto discutindo as bases teórico-metodológicas que têm me permitido transformar a questão geral sobre "o que ensinamos em Educação Física?" em uma problemática específica das pesquisas sobre a atividade pedagógica a partir dos fundamentos da Teoria Histórico-Cultural. Em seguida, analiso uma situação de ensino e de aprendizagem com o "conteúdo" circo, discutindo a relação entre os conhecimentos de ensino em Educação Física e um ensino promotor do desenvolvimento dos sujeitos, professores e estudantes. Por fim, procuro sistematizar as discussões sobre um ensino "Histórico-Cultural” para a Educação Física retomando a centralidade que a categoria "significados das atividades da cultura corporal" (COLETIVO DE AUTORES, 1992) tem para uma compreensão e proposição sobre a especificidade de um "ensino desenvolvimental" no campo da Educação Física escolar.

\section{O problema sobre "o que ensinamos" em Educação Física como uma problemática de pesquisa na perspectiva Histórico-Cultural}

Uma das questões mais gerais e, ao mesmo tempo, mais imediatas de serem resolvidas pela prática docente diz respeito à determinação de quais são os conhecimentos a serem ensinados e aprendidos na dinâmica do trabalho pedagógico. Determinar “o que ensinar”, em suas articulações dialéticas com o "como ensinar" e o "para quem ensinar", constitui-se em elemento central da 
atividade docente e se materializa nos processos de organização das ações de ensino e de aprendizagem na escola.

No campo da Educação Física escolar essa questão sobre quais são os conhecimentos de ensino da área é reconhecida por muitos autores como uma problemática geral (por exemplo, ver discussões de Bracht (1999), Siedentop (2002), Coletivo de Autores (1992), Vago (2009)). Ocorre que as diferentes respostas dadas a essa questão, por exemplo, se ensinamos "atividade física", ou "movimento" ou "corporeidade" ou "cultura corporal", anunciam diferentes concepções que fundamentam nosso olhar para a própria atividade pedagógica da Educação Física.

Para tratar desse problema geral sobre "o que ensinamos" em Educação Física a partir de uma perspectiva Histórico-Cultural da atividade pedagógica proponho, inicialmente, discutir uma questão que parece ser ainda bastante sensível em nossa área: o papel do ensino dos movimentos corporais na atividade pedagógica da Educação Física. Se, como dizia Vitor Marinho Oliveira (2004, p. 104), ainda em 1983 e sob uma perspectiva "humanista" da Educação Física: "A característica essencial da Educação Física é o movimento. É movimento. Não há Educação Física sem o movimento humano, e isto a distingue das demais disciplinas", o que nos parece imprescindível é discutir o próprio conceito de "movimento" que fundamenta nosso olhar para o ensino das práticas corporais na escola.

Considerando a tradição da perspectiva Crítico-Superadora da Educação Física "é fundamental [...] o desenvolvimento da noção de historicidade da cultura corporal" (COLETIVO DE AUTORES, 1992, p. 39), o que inclui uma historicidade dos próprios "movimentos corporais".

É preciso que o aluno entenda que o homem não nasceu pulando, saltando, arremessando, balançando, jogando etc. Todas essas atividades corporais foram construídas em determinadas épocas históricas, como respostas a determinados estímulos, desafios ou necessidades humanas [...].

Por isso se afirma que a materialidade corpórea foi historicamente construida e, portanto, existe uma cultura corporal, resultado de conhecimentos socialmente produzidos e historicamente acumulados pela humanidade que necessitam ser retraçados e 
transmitidos para os alunos na escola. (COLETIVO, 1992, p. 39, grifos meus).

Um dos fundamentos desta posição sobre a cultura corporal delineada pelo Coletivo de Autores encontra-se na conceituação marxiana sobre atividade humana, como a ação dos sujeitos em relação a determinadas necessidades surgidas pela prática social. Como sintetizam Marx e Engels (2007, p. 33),

Mesmo que o mundo sensível [...] seja reduzido a um cajado, a um mínimo, ele pressupõe a atividade de produção desse cajado. A primeira coisa a fazer em qualquer concepção histórica é, portanto, observar esse fato fundamental em toda a sua significação e em todo o seu alcance e a ele fazer justiça.

Parafraseando os autores poderíamos dizer: "mesmo que os conhecimentos de ensino da Educação Física sejam reduzidos a um mínimo, digamos ao movimento corporal, ainda assim esse 'movimento corporal' pressupõe a atividade humana que o produziu". Esse é o sentido geral de afirmarmos o caráter histórico-cultural das atividades da cultura corporal e, consequentemente, a dimensão histórica dos conhecimentos de ensino da Educação Física. À Educação Física cabe ensinar atividades humanas, como síntese da relação entre necessidades historicamente surgidas no campo das práticas corporais lúdicas e os meios capazes de satisfazer tais necessidades (NASCIMENTO, 2014).

Pode-se evidenciar, então, uma primeira expressão da problemática sobre "o que ensinamos em Educação Física" considerando os fundamentos da Teoria Histórico-Cultural: a necessidade de se explicitar as relações sociais específicas que estão materializadas nas diferentes atividades da cultura corporal.

Nesta perspectiva, podemos entender que as atividades da cultura corporal sintetizam em seus significados o processo histórico e cultural de transformação de todo e qualquer movimento corporal em uma forma socialmente determinada deste movimento. Para o gênero humano não existe o "salto", a "cambalhota", "o arremesso" etc. como movimentos corporais em si, aos quais, a posteriori, seriam acrescentados significados sociais, tal qual um rótulo é acrescentado a uma embalagem. O "saltar" - para o homem - nasce e se desenvolve em resposta a uma ou outra necessidade surgida na prática social, responde a uma determinada relação entre fins e meios, configurando-se em um processo que transformou e 
segue transformando de maneira decisiva a relação de cada sujeito singular com o "saltar".

Assim, um movimento de "salto" direcionado ao objetivo de produzir uma forma artística (caso de um "salto" realizado nas atividades de Dança, Mímica ou Circo) ou à produção de uma marca para uma destreza corporal (caso do "salto" realizado nas atividades de Ginástica ou Atletismo), ou, ainda, à produção de uma situação de oposição lúdica (caso do "salto" realizado na atividade de Jogo ou Luta) não pode ser compreendido como uma equação do tipo "salto + significado". Esses "saltos" são, eles mesmos, seus significados. São formas que expressam e, acima de tudo, realizam para cada sujeito singular as significações sociais historicamente surgidas no campo das práticas corporais lúdicas. Justifica-se, assim, a relevância e atualidade do conceito de "significações objetivas"2" da cultura corporal (COLETIVO DE AUTORES, 1992) para pensarmos "o que ensinamos" em Educação Física em uma perspectiva Histórico-Cultural da formação humana.

Como uma primeira definição, podemos dizer que esses significados referem-se às representações, ideias ou conceitos produzidos pela consciência social e que dizem respeito "ao lúdico, ao artístico, ao agonístico, ao estético ou outros" (COLETIVO DE AUTORES, 1992, p. 62). Embora esteja claro para essa perspectiva que o "movimento corporal" não é, em si, o conhecimento com o qual a Educação Física trabalha, deve estar igualmente claro para nós que é apenas por meio desses movimentos e nesses movimentos que os significados das atividades da cultura corporal se realizam. Eis um paradoxo que precisamos enfrentar no ensino da Educação Física: ao mesmo tempo em que os significados da cultura corporal não podem ser expressos diretamente nos movimentos corporais, esses significados só podem ser expressos por meio desses movimentos.

O problema pedagógico que esse paradoxo coloca para a atividade pedagógica da Educação Física não está, assim, no fato das crianças "fazerem movimentos corporais" nas aulas de Educação Física ou mesmo de aprenderem

2 No Coletivo de Autores o conceito de significados aparece, às vezes, com a expressão "significações objetivas". Conceitualmente, consideramos e assumimos neste texto que as palavras "significado" e "significação" expressam um mesmo conteúdo: são simultaneamente produto e processo da atividade humana. 
técnicas ou habilidades da dança, do jogo, da luta, da ginástica etc. $\mathrm{O}$ problema pedagógico está na qualidade dos objetivos e dos problemas propostos no ensino para que esses sujeitos façam esses "movimentos corporais" do jogo, da dança, da luta etc. na dinâmica da atividade pedagógica da Educação Física. A questão, assim, está em organizar ações de ensino e de estudo que permitam aos sujeitos atuarem com o problema fundamental que levou a humanidade à produção de um determinado conhecimento (DAVIDOV, 1988; MOURA et al 2016), tornando esse problema humano, historicamente formado, em um problema para-si (em um objetivo geral de sua atividade).

Quais seriam, então, esses objetivos e problemas que poderiam sintetizar os significados das atividades da cultura corporal e que, assim, deveriam ser postos como objetos ${ }^{3}$ das atividades de ensino e de estudo dos sujeitos nas aulas de Educação Física? Como, na especificidade deste campo de conhecimento, podemos contribuir para concretizar o princípio de que cada ser singular reconstitua para si as máximas possibilidades de desenvolvimento já alcançadas pela humanidade? (VYGOTSKI, 1995; 1997; VYGOTSKY, 2004; LEONTIEV, 1983).

Uma primeira posição a esse respeito refere-se à compreensão que o pensamento teórico, como uma forma específica de desenvolvimento dos sujeitos a partir do ensino escolar, refere-se a um modo de ação em que o sujeito torna-se capaz de se conscientizar sobre o seu próprio pensamento (VIGOTSKI, 2009). O pensamento teórico, sendo um processo permanente da atividade do sujeito na direção de refletir para-si o mundo de atividades humanas em suas muitas e diversas relações, de modo que esse sujeito compreenda que um conhecimento qualquer expressa, sempre, um determinado processo de produção deste conhecimento (DAVIDOV, 1988), pode se dar a partir das diferentes áreas de conhecimento, a depender do modo como o ensino é organizado.

Nesse sentido, os conhecimentos a serem ensinados no campo da Educação Física em direção à efetivação de um ensino desenvolvimental devem permitir que professores e educandos compreendam cada conhecimento particular da área

\footnotetext{
${ }^{3}$ Sobre o conceito de objeto da atividade ver Leontiev (1983).
} 
como produto de determinadas necessidades surgidas na prática social e, simultaneamente, como parte de um determinado sistema de conhecimentos.

Uma segunda posição que tenho defendido (NASCIMENTO, 2014) é a de que as atividades da cultura corporal, ao sintetizarem modos de ação para a criação dos significados "lúdico", "estético", "artístico", "agonístico" etc. podem contribuir para o desenvolvimento da capacidade de imaginação dos sujeitos, como uma das formas de manifestação das "funções psíquicas superiores" (VYGOTSKI, 1996).

A dimensão criadora das atividades da cultura corporal expressa-se ao evidenciar para os sujeitos a capacidade humana de transformar um determinado fenômeno daquilo que ele é naquilo que ele pode vir a ser. "É precisamente a atividade criadora do homem a que faz dele um ser projetado ao futuro, um ser que cria e transforma seu presente" (VIGOTSKY, 2004, p. 6).

Essa capacidade criadora permite que o sujeito construa para si uma imagem antecipada do produto da atividade na qual participa, permite antecipar em sua consciência a finalidade almejada, criando, então, uma imagem desta atividade. A criação desta imagem tem a função específica de transformar a realidade na própria consciência, modificar a realidade antecipadamente na consciência antes de transformá-la na prática.

[...] a imaginação como fundamento de toda atividade criadora se manifesta decididamente em todos os aspectos da vida cultural fazendo possível a criação artística, científica e técnica. Neste sentido, absolutamente tudo o que nos rodeia e foi feito pela mão do homem, todo o mundo da cultura diferentemente do mundo da natureza, é produto da imaginação e da criação humana pautada nessa imaginação. (VIGOTSKY, 2004, p. 7, tradução minha).

A importância da imaginação para os processos de formação dos sujeitos e, assim, para o próprio processo educativo, não se reduz à "criação do novo" do ponto de vista da humanidade. Como diz Vigotski, todos os objetos da vida cotidiana "[...] sem excluir os mais simples e ordinários são, por assim dizer, $a$ imaginação cristalizada" (VIGOTSKY, 2004, p.7, grifos do autor). Por isso mesmo, “[...] há que se diferenciar suas expressões como antecipação mental dos 
produtos da atividade do indivíduo - ainda que tais produtos não sejam objetivações originais, e a imaginação criadora do dado realmente "novo" ou inédito" (MARTINS, 2011, p. 182). O fundamental, assim, é que ao criar uma forma artística com um movimento corporal, por exemplo "um salto", o sujeito possa descobrir-se como criador da atividade humana que dá significado e sentidos a esse salto: por exemplo, ser um sujeito criador da dança ou do circo.

Saber-se criador dessas atividades humanas é condição indispensável para buscar descobrir os meios necessários e historicamente elaborados para se reproduzir intencionalmente os produtos de tais atividades. O sujeito, então, vai se apropriando da capacidade humana de imaginação, da capacidade de antecipar os resultados almejados e projetá-los no presente, de modo a ter nesses resultados orientações efetivas para suas ações. Essa capacidade humana de imaginação no campo dos conhecimentos da Educação Física escolar encontra-se materializada, sinteticamente, na ideia dos significados das atividades da cultura corporal, inicialmente proposta e elaborada pelo Coletivo de Autores (1992).

\section{Um caminho metodológico: um episódio de ensino e de aprendizagem para desencadear o debate}

Trago, neste item, uma discussão sobre a relação entre os conhecimentos de ensino da Educação Física escolar e os significados das atividades da cultura corporal. Para isso, analiso uma situação concreta de ensino e aprendizagem com o circo, em que se buscou trabalhar os processos de criação artística no campo da cultura corporal ${ }^{4}$. A discussão dessa situação é realizada por meio de um episódio de ensino (MOURA, 2004), compreendido como um recurso metodológico para a exposição dos resultados de uma pesquisa no campo da atividade pedagógica. Trata-se da organização de:

[...] frases escritas ou faladas, gestos e ações que constituem cenas que podem revelar interdependência entre os elementos de uma

\footnotetext{
4 Trata-se de uma proposição pedagógica realizada no contexto de uma pesquisa de mestrado (NASCIMENTO, 2010), envolvendo doze alunos da $4^{\mathrm{a}}$ série (atual $5^{\circ}$ ano) do Ensino Fundamental I e três estudantes do curso de Pedagogia que atuaram como professores-estagiários. Foram realizados 10 encontros, com duração de 3 horas cada. As aulas foram gravadas em vídeo e, posteriormente, transcritas. Os sujeitos participantes da pesquisa e/ou seus responsáveis assinaram termo de consentimento para esse fim.
} 
ação formadora. Assim, os episódios não são definidos a partir de um conjunto de ações lineares. Pode ser que uma afirmação de um participante de uma atividade não tenha impacto imediato sobre os outros sujeitos da coletividade [...]. (MOURA, 2004, p. 276).

A atividade pedagógica retratada neste episódio de ensino buscou destacar como significado objetivo para as ações de ensino e de estudo do circo o processo de criação de cenas com as personagens circenses. Esse significado aparece para o sujeito e realiza-se em sua atividade como um produto de sua atuação com as relações estruturais ou substanciais que compõem a criação de cenas circenses: a dinâmica entre a proposição de uma intencionalidade artística e o desenvolvimento de um enredo da cena (NASCIMENTO, 2010). A atuação dos sujeitos com esse significado é mediada pelos conceitos relacionados ao processo de criação de cenas: os conceitos de ângulo de visão em relação ao público, organização das ações corporais no tempo e espaço e os próprios conceitos de intencionalidade artística e enredo. Esses conceitos, sistematizados a partir de uma análise lógico-histórica (KOPNIN, 1978) do circo como síntese de relações sociais no campo da arte, passam, então, a desempenhar o papel de instrumentos para a ação dos sujeitos nos processos de ensino e estudo sobre a "criação de cenas com as personagens circenses”.

No episódio de ensino descrito no Quadro 1 destaca-se a relação do estudante Luis $^{5}$ com o processo de estudo do circo, considerando o seu envolvimento com a personagem do malabarista.

Quadro 1 - episódio de ensino: a relação do estudante Luis com o estudo do circo.

\section{CENÁRIO I: A aproximação de Luis com a personagem malabarista}

Após as experimentações de alguns movimentos das personagens do circo (aula 3), Luis fica brincando com as bolinhas de malabares, utiliza às vezes apenas uma mão e às vezes as duas mãos. Luis mostra certo domínio sobre como fazer os movimentos de malabarismo.

Os educadores começam a conversar com as crianças, a partir de seus interesses, sobre quais personagens iriam compor o espetáculo (aula 4). Luis ratifica sua intenção em ser o malabarista, anunciada nas primeiras aulas, antes mesmo do estudante realizar os movimentos de malabarismo.

- Luis: "Eu sou o malabarista, não quero nem saber!"

\footnotetext{
${ }^{5} \mathrm{O}$ nome do sujeito foi alterado.
} 


\section{CENÁRIO II: O planejamento e o ensaio da cena de malabarismo}

A tarefa proposta para todos os grupos (aula 5) era a de iniciar o ensaio das cenas que foram planejadas na aula anterior. Luis começa seu ensaio. Ele faz o movimento de malabarismo com as bolinhas repetidas vezes. Uma educadora, que havia acompanhado o planejamento escrito para a cena do malabarista, intervém no ensaio de Luis. A professora relembra com ele a ideia da cena que ele havia criado: "eu começo jogando as bolas para o alto e sempre as bolinhas vão cair na minha cabeça e depois eu vou fazer certinho". Luis ouve e discute algumas ideias para concretizar essa intenção previamente planejada. Quando a educadora se afasta, contudo, Luis volta a fazer os movimentos de malabarismo tal qual anteriormente. Depois de alguns minutos uma segunda educadora tenta auxiliá-lo no ensaio da cena engraçada que ele havia planejado. Novamente, Luis ouve e discute as ideias com a educadora, mas no momento em que é deixado sozinho, ele realiza apenas os movimentos corporais de malabares: nenhuma ação de Luis indica que ele esteja ensaiando algum aspecto da cena que havia planejado.

\section{CENÁRIO III: Apresentando a cena para os colegas}

Os estudantes estavam preparando uma primeira apresentação das cenas que estavam ensaiando para os colegas da turma e os educadores (aula 6). No momento da cena do malabarista, Luis demonstra uma preocupação com a execução dos seus movimentos.

Luis: [já dentro do palco] "mas eu não treinei direito...".

Prof II: "[faz] do jeito que você treinou".

A cena de Luis é basicamente a execução dos movimentos de malabarismo. A cena planejada inicialmente ou mesmo elementos que permitissem identificar uma organização de um começo, um meio e um fim para a cena estavam ausentes. No final da apresentação, Luis demonstra certa irritação por ter deixado as bolinhas caírem muitas vezes.

\section{CENÁRIO IV: A relação do Luis com os ensaios da cena de malabarismo: ensaio da cena ou treino dos movimentos?}

Durante a elaboração de um material para o cenário (aula 7), Luis manifesta sua necessidade e vontade de "treinar" os movimentos do malabarista.

Luis "Cadê as bolinhas [para professora]? Eu tenho que treinar, que eu não sei fazer direito"

Prof II: "Você está treinando em casa Luis?".

Luis "Eu parei, preciso treinar".

Prof II: "Volta a treinar em casa, porque só o treino aqui não vai dar, né?".

Luis: "Onde estão as bolinhas?".

Prof II: "Agora não é hora de treinar, daqui a pouco você treina, tá?".

Passam quase doze minutos e Luis volta a insistir:

Luis: "Que horas são?".

Alguém: "Dez e meia".

Luis: "Oh! Nós não vamos treinar?!".

Passam cerca de 20 minutos desde sua última fala e ele volta a insistir:

Luis [para professora]: "Cadê as bolinhas?!".

A professora ainda diz que não está na hora do treino. Precisam fazer a tarefa do

cenário. Passam-se mais 10 minutos e Luis questiona novamente a educadora:

Luis "Agora eu quero treinar, cadê as bolinhas?!".

Luis começa o seu "treino". Uma professora se aproxima e procura orientá-lo em seu 
ensaio.

Prof II: "Quando você treinar em casa, você vai ver quantas vezes você consegue fazer, porque daí, no dia da apresentação, ao invés de chegar e deixar cair [as bolinhas] você para antes. Se você consegue fazer três [vezes], você faz três e para; faz mais três e para... depois faz com uma mão só”.

\section{CENÁRIO V: A desistência em fazer a cena do malabarismo.}

No penúltimo ensaio geral (aula 9) e antes de iniciarmos a apresentação das cenas para os colegas, Luis procura a professora para dizer da sua desistência em fazer a cena do malabarismo. Ele justifica que não consegue fazer os movimentos direito e, mesmo com a insistência da professora para que faça do jeito que sabe e consegue, ele se recusa a continuar a fazer esta cena. Luis passará a fazer a cena dos equilibristas com bastão.

Fonte: Elaboração da autora (adaptado de Nascimento, 2010)

Luis quer ser o malabarista do espetáculo circense ("Eu sou o malabarista, não quero nem saber!" - cenário I) e planeja sua cena como malabarista de modo a envolver uma parte cômica ("eu começo jogando as bolas para o alto e sempre as bolinhas vão cair na minha cabeça” - cenário II) e uma de destreza (“...e depois eu vou fazer certinho" - cenário II). Nota-se que, ainda que sucintamente, o seu planejamento escrito expressa a existência de uma "cena", com um enredo e uma intencionalidade de comunicação para um público. Entretanto, a realização dessa cena elaborada por Luis não se materializou nenhuma vez nas ações de estudo que ele realizou e que foram propostas pelas professoras (cenários II e III). O problema de criação de uma cena com a personagem circense não parece ter se tornado um objetivo orientador de suas ações: Luis treina os movimentos de malabares, mas não ensaia sua cena (cenários II, III e IV).

Para Luis, então, e especificamente no que diz respeito a sua relação com a personagem malabarista, o circo não pôde ser mais do que a ação de realizar, com certo grau de perfeição, o movimento corporal das personagens. É devido a este sentido que Luis atribuía ao circo que ele desiste da cena de malabarista (cenário V) um dia antes da apresentação final do espetáculo: Luis percebe que não poderia atingir o padrão de perfeição do movimento corporal que ele mesmo gerou para si, ao mesmo tempo em que não consegue encontrar outro meio de realizar uma cena com o malabarista que não fosse a "cena" de executar os movimentos corporais da personagem. 
Do ponto de vista da intencionalidade pedagógica proposta nesta atividade de ensino com o circo notam-se, nos cenários II e III, algumas ações de ensino que buscavam destacar o processo de criação de uma cena com as personagens, como o objeto das ações de estudo sobre o circo: a) elaborar um planejamento escrito da cena; b) ensaiar as cenas; c) apresentar as cenas para os colegas e professores e d) analisar as cenas apresentadas considerando os elementos conceituais que compõem essa criação (ângulo de visão - organização dos movimentos corporais no tempo e espaço- intencionalidade artística - enredo). Notam-se, também, algumas falas das professoras para Luis buscando tornar o processo de criação da cena com a personagem malabarista o foco de suas ações, por exemplo: i) contar quantas vezes conseguia fazer o malabarismo e parar antes disso para evitar que as bolinhas caíssem no chão e, assim, poder prosseguir a cena; ii) dar uma volta pelo palco e fazer os movimentos cada vez para uma direção; iii) fazer algumas vezes apenas com uma mão, já que ele tinha um bom domínio desse movimento; iv) treinar em casa para sentir-se mais seguro; v) terminar a cena de um jeito especial, por exemplo, abrindo os braços com as bolinhas nas mãos e agradecer; vi) ensaiar a ideia da cena engraçada, deixando as bolinhas caírem na cabeça.

Deste modo, do ponto de vista do ensino, o processo de criação de cenas com as personagens circenses apresentou-se como o significado mais geral desta atividade pedagógica: ocupava o centro do sistema de conhecimentos e do sistema de ações de estudo que se propôs trabalhar. Para Luis, contudo, essas ações de estudo propostas não puderam se efetivar como mediações entre o significado social destacado na atividade circense (o processo de criação de cenas com as personagens) e o sentido pessoal que Luis já tinha sobre o "circo" (realizar de forma "perfeita" os movimentos corporais das personagens).

Apesar de realizar as ações de estudo propostas pelas professoras (planejar sua cena; ensaiar a cena; apresentar para os colegas etc.), Luis não pôde transformar essas ações de modo a efetivamente engajar-se com elas como ações de sua atividade de estudo sobre o circo. Luis não pôde estabelecer para si o objetivo geral de compreender como se criam cenas circenses. É importante, agora, buscarmos explicar o porquê dessa não possibilidade de transformação das 
ações de estudo realizadas por Luis em uma atividade de estudo: na sua atividade de estudo (DAVIDOV, 1988).

Poderíamos considerar, inicialmente, que a necessidade de um domínio mais ou menos habilidoso de um determinado movimento corporal, caso do malabares, seja um fator central para explicarmos a cisão entre o planejamento escrito da cena e a concretização desse planejamento nas ações de ensaios e nas apresentações do estudante. Se não temos autonomia mínima para realizar, por exemplo, o movimento corporal de malabares, as nossas possibilidades objetivas de construir e realizar uma cena com o malabarista tornam-se bastante reduzidas. Entretanto, esse não parecia ser o caso de Luis.

Desde o início do trabalho pedagógico (cenário I), Luis demonstrou ter algum domínio deste movimento corporal, sendo capaz de realizar três ou quatro sequências completas com duas bolinhas, utilizando ora as duas mãos ora apenas uma mão. Sendo assim, poderíamos dizer que Luis tinha uma relativa autonomia para fazer o "movimento corporal" de malabares, o que lhe permitiria se relacionar com os processos de criação de uma cena com o malabarista.

No decorrer da atividade pedagógica, contudo, foi se evidenciando que o sentido que Luis trazia sobre o que era realizar uma cena com o malabarista constituía-se em uma orientação mais efetiva para suas ações de estudo do circo do que os objetivos e problemas apresentados no significado de criação de cenas com as personagens circenses.

Utilizando a conceituação de motivo de Leontiev (1988; 1983) poderíamos dizer que "construir uma cena circense" era um motivo compreensível para Luis: ele compreendia que esse era o objetivo de todo o trabalho pedagógico com o circo que estava sendo realizado. Mas a compreensão desse objetivo não podia mobilizá-lo para um engajamento pessoal na busca de resolução desse problema: o motivo era compreensível, mas não era eficaz (LEONTIEV, 1988) em relação a um envolvimento efetivo de Luis com as ações de estudo propostas.

Um dos problemas pedagógicos centrais que esse episódio nos permite discutir começa precisamente aqui: no reconhecimento da não linearidade entre o ensino e a aprendizagem ou, o que dá no mesmo, na possibilidade de não existir 
uma coincidência entre o significado social que se propõe para o ensino e o sentido pessoal que o estudante estabelece com o conteúdo que está sendo trabalhado ${ }^{6}$. Luis não pôde transformar o problema de ensino proposto em um problema para-si, o que o impediu de se colocar efetivamente em atividade de estudo (DAVIDOV, 1988) a partir das ações de estudo propostas pelos professores.

Evidencia-se, assim, que a atividade de estudo constitui-se em um produto da atividade de ensino do professor tão somente na medida em que o estudante, ele mesmo, possa transformar as ações de estudo propostas pelo professor em ações de estudo para-si: possa assumir conscientemente os objetivos de ensino como os seus objetivos de aprendizagem. É por essa razão que uma das centralidades do trabalho docente seja, justamente, a proposição e organização de ações de estudo que permitam expressar os significados ou os problemas substanciais que devem ocupar o papel de objeto das atividades de ensino e de estudo de professores e estudantes.

Como vimos em nosso episódio, o significado da atividade circense que se buscou trabalhar nessa atividade pedagógica (o processo de criação artística de cenas com as personagens circenses) não pôde se realizar para Luis. Mas é somente tendo clareza sobre qual significado se pretendia trabalhar na atividade pedagógica que podemos analisar o percurso singular de cada estudante com a apropriação dos conhecimentos de ensino propostos, bem como avaliar a sua inserção ou não em uma atividade de estudo (DAVIDOV, 1988)7.

No caso da atividade pedagógica retratada no episódio de ensino aqui apresentado, esse significado estava expresso na relação entre a proposição de

\footnotetext{
${ }^{6}$ A busca de uma coincidência, o que não quer dizer identidade, entre o significado social e o sentido pessoal constitui-se em uma problemática geral para os processos de organização do ensino na Teoria Histórico-Cultural. A esse respeito ver, por exemplo, os trabalhos de Asbahr (2011); Araújo (2017) e Rubinstein (1973).

${ }^{7}$ Nesse sentido é importante destacar que o processo de estudo do circo também se realizou para Luis durante as análises das cenas dos demais colegas, momento em que o estudante apresentava, muitas vezes, um olhar atento aos elementos e relações que nos permitem pensar o processo de criação de cenas com as personagens circenses. Por exemplo, em um momento em que se discutia a realização da cena da "centopeia", Luis protagoniza a seguinte situação:

Prof II: “... será que pro público ver [...]é melhor fazer a centopeia de frente para vocês ou de lado para vocês?

Luis: "De lado"

Algumas crianças: "de frente"

Prof II: "Por que de lado, Luis?"

Luis: "porque daí mostra mais coisa, mais as pessoas (...) vai mostrar quantas pessoas têm...”.
} 
uma intencionalidade artística e o desenvolvimento de um enredo para a cena, considerando como elementos mediadores desse processo a organização do ângulo de visão e a disposição dos movimentos corporais no tempo e espaço. Destacar esse significado como objeto de ensino e de aprendizagem permite que os sujeitos subordinem as diferentes ações relacionadas com o circo (da realização dos "movimentos corporais" das personagens à escolha das roupas e cenários) a esse problema geral de "como se criam cenas com as personagens circenses".

Para os educadores, o processo de criação das cenas com as personagens circenses apresenta-se como a referência e o ponto de partida concreto para a sua atividade de organização do ensino. Para os educandos, esse significado constituise no problema a ser resolvido durante todo o percurso de ensino e aprendizagem e, assim, transforma-se - pelo seu engajamento nas ações de estudo propostas em um primeiro ponto de chegada de sua aprendizagem: o problema de criação de uma cena passa a ser um problema pessoalmente significativo para o sujeito e, assim, permite com que o sujeito se insira efetivamente em uma atividade de estudo com o circo.

É possível considerar que em um atividade pedagógica da Educação Física com o circo sejam propostos outros objetivos de ensino e aprendizagem, por exemplo, estudar o circo para aprender a fazer cambalhota ou para estudar a história do circo ou para aprender a trabalhar em grupo etc. Mas a proposição desses diferentes objetivos de ensino não contradiz o fato de que o processo de criação de cenas com as personagens seja, objetivamente, um problema nuclear desta atividade humana: um significado substancial que surgiu na prática social durante o processo de desenvolvimento do circo como uma atividade artística. É por essa razão que a determinação desses significados das atividades da cultura corporal se apresenta como condição estruturante para a organização do ensino da Educação Física em uma perspectiva Histórico-Cultural da formação humana.

Destacar esse ou aquele significado sobre uma atividade da cultura corporal, significado esse que sintetiza os problemas substanciais relacionados aos processos de criação das atividades de jogo, dança, luta, ginástica, circo etc., determinam as possibilidades formativas que são propostas para os sujeitos em 
suas atividades de ensino e de estudo com as atividades da cultura corporal. A explicitação desses significados apresenta-se, assim, como um dos elementos mais determinantes da atividade pedagógica da Educação Física: é a partir deles que se dá a possibilidade de proposição de um sistema de conhecimentos para a área.

A apropriação desses significados das atividades da cultura corporal pelos educandos não é imediata, direta ou linear. Como vimos em nosso episódio ela pode, para alguns alunos, não se realizar no tempo pedagógico considerado. Entretanto, eleger esse ou aquele significado como objeto de ensino da atividade pedagógica transforma de maneira decisiva as possibilidades de ações dos sujeitos em suas ações de ensino ou de estudo com as atividades da cultura corporal.

\section{Os significados das atividades da cultura corporal e os conteúdos de ensino da Educação Física}

A proposição sobre "o que ensinamos" em Educação Física parte, muitas vezes, da definição de uma ou outra manifestação corporal que os educandos deveriam conhecer, por exemplo, os jogos, as lutas, as danças etc. ou, ainda, de jogos, danças e lutas específicas: o futebol, ou o judô, ou o frevo. Entretanto, considerando que todas essas manifestações corporais são formas que expressam uma ou outra atividade humana, o ponto de partida efetivo para a organização do ensino da Educação Física em uma perspectiva Histórico-Cultural reside menos nessa definição inicial de quais "práticas corporais" iremos trabalhar e mais na explicitação das significações historicamente surgidas e desenvolvidas na esfera da cultura corporal.

Podemos compreender, conforme Leontiev (1983), que os significados refletem o mundo objetivo na consciência do homem.

A significação é aquela generalização da realidade que foi cristalizada, que se fixou em seu portador sensitivo, no geral, uma palavra ou combinação de palavras. Esta é a forma espiritual, ideal de cristalização da experiência social, da práxis social da humanidade [...]. O homem conhece o mundo não como Robson, fazendo uma descoberta depois da outra em uma ilha deserta. $\mathrm{O}$ homem, no curso de sua vida, assimila a experiência da humanidade, a experiência das gerações precedentes, que tem lugar precisamente na forma de domínio das significações [...], a 
significação é a forma na qual um homem determinado chega a dominar a experiência da humanidade, refletida e generalizada. (LEONTIEV, 1983, p. 225, grifos nossos).

Quando falamos, então, sobre os significados das atividades da cultura corporal - inicialmente, "o lúdico, o artístico, o estético, o agonístico ou outros", Coletivo de Autores (1992, p. 62), estamos nos referindo a determinadas experiências históricas e socialmente gestadas pela atividade humana.

A identificação do conteúdo objetivo de cada uma dessas significações, identificar os "nexos conceituais" ou as "relações substanciais" para as diferentes áreas de conhecimento, foi um problema fundamental na teoria de Davidov sobre o ensino desenvolvimental (DAVIDOV, 1988; DAVYDOV, 1982). Trata-se, justamente, da tentativa de propor e sistematizar o conjunto de relações sociais que constituíram e seguem constituindo uma dada atividade humana e que se encontram sintetizadas nos conceitos, princípios e tópicos de uma área de conhecimento.

É em virtude dessa compreensão específica dos conceitos de significado e de atividade (LEONTIEV, 1983; MARX, 2004; MARX e ENGELS, 2007) que podemos considerar a ideia dos "significados das atividades da cultura corporal", inicialmente delineada pelo Coletivo de Autores (1992), como um instrumento nuclear para a proposição de uma problemática de pesquisa sobre "o que ensinamos" em Educação Física a partir dos fundamentos da Teoria HistóricoCultural. Trata-se de um instrumento para nosso permanente engajamento na busca de explicações sobre quais são as relações sociais específicas que estão objetivadas na dança, no circo, na mímica, na luta, no jogo, no atletismo, na ginástica etc. e que permitem aos sujeitos se apropriarem dos modos de ação para criarem/recriarem tais atividades para-si.

Quando destacamos que o significado central do circo é o artístico e que, dentro dele, o problema específico refere-se à criação de cenas com as personagens circenses, podemos determinar de forma mais concreta o sistema de conhecimentos que deverá orientar a atividade pedagógica da Educação Física com o estudo do circo. Conseguimos determinar as relações objetivas com as quais os sujeitos da atividade pedagógica, professores e estudantes, devem se relacionar 
para reconstituírem para si o circo como uma atividade artística, como síntese entre a dinâmica de proposição de uma intencionalidade artística e o desenvolvimento de um enredo da cena.

A apropriação desses significados não implica apenas ou principalmente a aquisição de "novas palavras" ou novas definições sobre o circo, repetindo, por exemplo, que "o circo é o processo de criação de cenas com as personagens". Tratase, isto sim, da aquisição de um novo modo de ação que efetivamente permita aos sujeitos reconstituírem para si o circo como uma atividade artística e, assim, agirem criadoramente com ele e a partir dele.

O processo de apropriação de conceitos teóricos permite aos sujeitos perceberem o mundo de outro modo e "perceber as coisas de modo diferente significa ao mesmo tempo ganhar outras possibilidades de agir em relação a elas. Como em um tabuleiro de xadrez: vejo diferente, jogo diferente" (VIGOTSKI, 2009, p.289). No caso de nosso exemplo com o circo, ao perceber de modo "diferente" o que é o circo, vê-lo efetivamente como um processo de criação de cenas, com toda a complexidade que esse problema envolve, permite aos educandos projetarem como objetivo de suas ações de estudo a "criação de uma cena com o malabarista, ou com o acrobata, ou com o contorcionista etc. do modo como um artista faz". Temos, aqui, o início da solução para o aparente paradoxo entre o "movimento corporal" e os "significados das atividades da cultura corporal" apresentado no início deste texto. Os movimentos corporais de cada uma dessas personagens são elementos que, tomados em si mesmos, ocultam o significado objetivo da atividade circense, assumem a forma de um movimento "em si". Mas, ao mesmo tempo, sem esses movimentos corporais específicos, sem essas formas, o significado da atividade circense não se realiza para o sujeito na sua relação com o circo.

A importância de conhecermos teoricamente esses significados objetivos das atividades da cultura corporal, conhecermos as características essenciais de cada atividade humana a ser ensinada no campo da cultura corporal, diz respeito à possibilidade que esse conhecimento nos dá para melhor agirmos na estrutura da atividade pedagógica. Sem conhecermos teoricamente essas significações que constituem as atividades da cultura corporal, os conteúdos de ensino da Educação 
Física acabam tornando-se simples "tópicos", uma lista de manifestações e/ou de conhecimentos que não compõem, ainda, um sistema conceitual.

Nessa direção, é preciso reconhecer os esforços coletivos de construção de uma Educação Física fundamentada na Teoria Histórico-Cultural, esforço esse expresso em teses, dissertações e artigos científicos ${ }^{8}$. Esses trabalhos buscam, em suas singularidades, formular e resolver problemáticas concretas sobre "o que ensinamos" e "como ensinamos" em Educação Física considerando uma perspectiva histórica e cultural da formação humana e considerando, ainda, a exigência de nos engajarmos em uma luta científica e, ao mesmo tempo, política em relação a essa proposição sobre o vir a ser da Educação Física escolar.

Trata-se de uma luta científica porque para efetivarmos um ensino que contribua para promover o "máximo desenvolvimento" de cada indivíduo (VYGOTSKI, 1997; LEONTIEV, 1978) precisamos propor quais seriam os conhecimentos substanciais no campo das atividades da cultura corporal que permitam expressar a dimensão teórica dos conceitos na especificidade da Educação Física. O que, precisamente, pode ser desenvolvido nos sujeitos a partir do jogo, da dança, da luta, da ginástica etc.? Contribuir para o "máximo desenvolvimento dos sujeitos" constitui-se, ao mesmo tempo, em uma luta política, porque esse desenvolvimento deve estar orientado à formação de uma personalidade coletivista (VYGOTSKY 2004; LEONTIEV, 1978), de modo que "o fim deste caminho, ao dizer de Gorki, é o homem convertido em homem da humanidade" (LEONTIEV, 1983, p. 180).

\section{Considerações finais: os significados das atividades da cultura corporal como ponto de partida das investigações sobre o ensino da Educação Física em uma Perspectiva Histórico-Cultural}

Busquei, neste ensaio, tecer algumas considerações sobre o sentido pedagógico presente ao falarmos de um ensino Histórico-Cultural na Educação

\footnotetext{
8 A título de ilustração desse processo coletivo cito dois grupos de estudo e pesquisa que vêm produzindo sistematicamente pesquisas fundamentadas na Teoria Histórico-Cultural, o GEPEFE (Grupo de Estudos e Pesquisa em Educação Física e Escola, coordenado pelo professor Vidalcir Ortigara e pela professora Ana Lucia Cardoso) e o LEPEL (Linha de Estudo e Pesquisa em Educação Física \& Esporte e Lazer, coordenado, em seu núcleo na UFBA, pela professora Celi Nelza Zulke Taffarel e pelo professor Cláudio de Lira Santos Júnior.
} 
Física. A partir da análise de um episódio de ensino realizado com o "circo", busquei explicitar alguns fundamentos que nos permitam transformar o problema geral sobre "o que ensinamos em Educação Física" em uma problemática específica de pesquisa no campo da Teoria-Histórico Cultural.

Uma premissa que orientou o modo de exposição dessas ideias no presente ensaio está na compreensão de que não podemos realizar na escola "um ensino Histórico-Cultural" simplesmente anunciando as potencialidades didáticas e educativas dos conceitos que foram desenvolvidos por seus autores. Parafraseando Vigotski que, em sua busca de criar uma psicologia HistóricoCultural, dizia: "Não quero receber de lambuja, pescando aqui e ali algumas citações, o que é a psique, o que desejo é aprender na globalidade do método de Marx como se constrói a ciência, como enfocar a análise da psique" (VIGOTSKI, 2004, p. 395), poderíamos também dizer: "Não queremos receber de lambuja, pescando aqui e ali algumas citações, o que é a atividade pedagógica da educação física, quais são os seus conhecimentos e modos de organização do ensino; o que desejamos é aprender na globalidade do método de Marx e na globalidade dos princípios teóricos da Teoria Histórico-Cultural como se constrói a análise da atividade pedagógica e do ensino da Educação Física”. Para tal, precisamos enfrentar a tarefa de formular problemáticas específicas em relação à atividade pedagógica da Educação Física.

Por essa razão, a relação entre a Teoria Histórico-Cultural e a Educação Física não se apresenta simplesmente como uma premissa para a atividade de professores e pesquisadores que lidam com os processos de ensino e de aprendizagem da Educação Física escolar, mas fundamentalmente como um ponto de chegada: uma "Educação Física Histórico-Cultural" como produto de nossas ações concretas com os conceitos, princípios e teses da teoria para a identificação e resolução das problemáticas específicas que perpassam a busca de um ensino promotor do desenvolvimento dos sujeitos no campo das atividades da cultura corporal. 


\section{Referências}

ARAÚJO, Elaine Sampaio. Organização do ensino e aprendizagem docente. Tese de Livre Docência - Faculdade de Filosofia Ciências e Letras de Ribeirão Preto, Universidade de São Paulo, São Paulo, 2017.

ASBAHR, Flavia da Silva Ferreira. "Por que aprender isso, professora?" Sentido pessoal e atividade de estudo na Psicologia Histórico-Cultural - Instituto de Psicologia da Universidade de São Paulo, 2011.

BRACHT, Valter. A constituição das teorias pedagógicas da educação física. Cadernos Cedes, ano XIX, nº 48, Agosto/99.

COLETIVO DE AUTORES. Metodologia do ensino da Educação Física. São Paulo: Cortez. 1992.

DAVIDOV, Vasili. V. La enseñanza escolar y el desarrollo psíquico: investigación teórica y experimental. Moscú: Editorial Progreso, 1988.

DAVYDOV, Vasili. V. Tipos de generalización en la enseñanza. Havana: Pueblo y Educación, 1982.

LEONTIEV, Alex N. Actividad, conciencia y personalidad. Havana: Pueblo y Educación, 1983.

O desenvolvimento do psiquismo. Lisboa: Livros Horizonte, 1978.

. Uma contribuição à teoria do desenvolvimento da psique infantil. In:

VIGOTSKII, L. S; LURIA, A. R; LEONTIEV, A. N. Linguagem, desenvolvimento e aprendizagem. São Paulo: ICONE, 1988 (p. 59-83).

KOPNIN, Pavel V. A dialética como lógica e teoria do conhecimento. Rio de Janeiro: Civilização Brasileira, 1978.

MARTINS, Ligia Márcia. O desenvolvimento do psiquismo e a educação escolar: contribuições à luz da psicologia histórico-cultural e da pedagogia históricocrítica. Tese (livre docência) - Universidade Estadual Paulista. Bauru, 2011.

MARX, Karl. Manuscritos econômico-filosóficos. São Paulo: Boitempo, 2004.

MARX, Karl; ENGELS, Friedrich. A ideologia alemã. São Paulo: Boitempo, 2007.

MOURA, Manoel Oriosvaldo de. A atividade de ensino como unidade formadora. Bolema. São Paulo, ano II, n.12, p. 29-43, 1996. 
. Pesquisa colaborativa: um foco na ação formadora. In: BARBOSA, Raquel Lazzari Leite (Org). Trajetórias e perspectivas da formação de educadores. São Paulo: Editora UNESP, 2004. (p. 257-285).

O educador matemático na coletividade de formação: uma experiência com a escola pública. 2000. $131 \mathrm{f}$. Tese (Livre Docência em Metodologia do Ensino de Matemática) - Faculdade de Educação, Universidade de São Paulo, São Paulo, 2000.

MOURA, Manoel Oriosvaldo et al. A atividade orientadora de ensino: unidade entre ensino e aprendizagem. In: MOURA, M. O (Org). A Atividade pedagógica na teoria histórico-cultural. Campinas: Autores Associados, 2016. (pp.93-126).

NASCIMENTO, Carolina Picchetti. A atividade pedagógica da Educação Física, a proposição dos objetos de ensino e o desenvolvimento das atividades da cultura corporal. 2014. 293 f. Tese (Doutorado em Educação) - Programa de PósGraduação em Educação, Faculdade de Educação, Universidade de São Paulo, São Paulo, 2014.

A organização do ensino e a formação do pensamento estético-artístico na teoria histórico-cultural. 2010. 249 p. Dissertação (Mestrado em Educação) Faculdade de Educação, Universidade de São Paulo, São Paulo, 2010.

OLIVEIRA, Vitor Marinho de. O que é educação física. São Paulo: Editora brasiliense, 11.ed, 2004.

RUBINSTEIN, Sergei. Princípios da psicologia geral. Lisboa: Editorial Estampa, 1973.

SIEDENTOP, Daryl. Content Knowledge for Physical Education. Journal of teaching in physical education, v. 21, n.4, p. 368-377, jul. 2002.

VAGO, Tarcísio Mauro. Pensar a educação física na escola: para uma formação cultural da infância e da juventude. Cadernos de Formação RBCE, p. 25-42, set. 2009.

VIGOTSKI, Lev Semionovich. Teoria e Método em Psicologia. São Paulo: Martins Fontes, 2004.

2009.

. A construção do pensamento e da linguagem. São Paulo: Martins Fontes,

VIGOTSKY, Lev Semionovich. Imaginación y creación en la edad infantil. Havana: Pueblo y Educación. 2004.

VYGOTSKI, Lev Semionovich. Obras Escogidas. Tomo III. Madri: Visor, 1995. Obras Escogidas. Tomo IV. Madri: Visor, 1996. 
Obras Escogidas. Tomo V. Madri: Visos, 1997.

VYGOTSKII, Lev Semionovich. Aprendizagem e desenvolvimento intelectual na idade escolar. In: VYGTOSKY, L. V; LURIA, A. R; LEONTIEV, A. N. Linguagem, desenvolvimento e aprendizagem. São Paulo: ED. Ícone, 1988. (p. 103-117).

VYGOTSKY, Lev Semionovich. A transformação socialista do homem. In: URSS: Varnitso, 1930. Tradução de Nilson Dória: Marxist Internet Archive, 2004. Disponível em:

<http://www.marxists.org/portugues/vygotsky/1930/mes/transformacao.htm>. Acesso em: 5 de jun. de 2018.

\section{Carolina Picchetti Nascimento}

Integrante do Grupo de Estudo e Pesquisa sobre Atividade Pedagógica (GEPAPe) e, atualmente, é professora do Departamento de Metodologia de Ensino da Universidade Federal de Santa Catarina. 